University of Nebraska - Lincoln

DigitalCommons@University of Nebraska - Lincoln

Faculty Publications, Department of Psychology

Psychology, Department of

February 2001

\title{
A Closer Look at the Nature of Intimate Partner Violence Reported by Women With a History of Child Sexual Abuse
}

\author{
David DiLillo \\ University of Nebraska-Lincoln, ddilillo@unl.edu \\ Dawn Giuffre \\ University of Missouri-Columbia, deg26b@mizzou.edu \\ George C. Tremblay \\ Antioch New England Graduate School, George_Tremblay@antiochne.edu \\ Lizette Peterson \\ University of Missouri-Columbia
}

Follow this and additional works at: https://digitalcommons.unl.edu/psychfacpub

Part of the Psychiatry and Psychology Commons

DiLillo, David; Giuffre, Dawn ; Tremblay, George C.; and Peterson, Lizette , "A Closer Look at the Nature of Intimate Partner Violence Reported by Women With a History of Child Sexual Abuse" (2001). Faculty

Publications, Department of Psychology. 106.

https://digitalcommons.unl.edu/psychfacpub/106

This Article is brought to you for free and open access by the Psychology, Department of at DigitalCommons@University of Nebraska - Lincoln. It has been accepted for inclusion in Faculty Publications, Department of Psychology by an authorized administrator of DigitalCommons@University of Nebraska - Lincoln. 


\title{
A Closer Look at the Nature of Intimate Partner Violence Reported by Women With a History of Child Sexual Abuse
}

\author{
David DiLillo, University of Nebraska-Lincoln \\ Dawn Giuffre, University of Missouri-Columbia \\ George C. Tremblay, Antioch New England Graduate School \\ Lizette Peterson, University of Missouri-Columbia
}

\begin{abstract}
This study provides an examination of violence occurring in the couple relationships of female survivors of childhood sexual abuse (CSA). Participants were 240 low-income women, 113 of whom (47\%) reported some history of CSA. Compared with non-sexually abused women, those who had experienced CSA reported that their couple relationships were more likely to have involved several severe forms of violence, including hitting, kicking, and beating. Comparisons of the directional patterns of partner violence revealed that a greater proportion of CSA survivors' relationships had involved at least one incident of both man-to-woman and woman-to-man aggression. An unexpected finding was that a significant number of all intimate relationships were reported by women to have involved one or more acts of woman-to-man violence only. Findings are discussed in the context of current knowledge about CSA and intimate partner violence; directions for future research are suggested.
\end{abstract}

Authors' Note: This research was sponsored in part by a grant from the Maternal and Child Health Bureau of the Health Resources and Service Administration (MCJ-290635). Correspondence regarding this article should be directed to David DiLillo, Department of Psychology, 238 Burnett Hall, University of NebraskaLincoln, Lincoln, NE 68588-0308.

$\mathrm{T}$ he negative long-term correlates of childhood sexual abuse (CSA) are numerous and varied. Women with a history of CSA report a multitude of individual mental health problems ranging from depression and anxiety to substance abuse and somatic complaints (Browne \& Finkelhor, 1986; Polusny \& Follette, 1995). Literature in this area has most often examined linkages between CSA and lat- 
er intrapersonal difficulties. If, as Finkelhor and Browne (1985) suggested, early sexual trauma can profoundly "alter a child's cognitive and emotional orientation toward the world and cause trauma by distorting the child's self concept, world view, or affective capacities" (p. 531), then there is reason to suspect that CSA may disrupt survivors' long-term interpersonal adjustment as well. Literature reviews have typically supported this possibility, noting general impairments in social and interpersonal functioning experienced by female sexual abuse survivors (Browne \& Finkelhor, 1986; J. L. Davis \& Petretic-Jackson, 2000; DiLillo, in press; Polusny \& Follette, 1995).

A flood of recent books in the popular press points to survivors' couple relationships as one area of interpersonal functioning that may be particularly susceptible to difficulties stemming from early sexual trauma (Cameron, 1995; Courtright \& Rogers, 1994; L. Davis, 1991; DeBeixedon, 1995; Engel, 1993; Gil, 1992; Graber, 1991; Hansen, 1991; Kritsberg, 1990; Levine, 1996; Matsakis, 1998; Stark, 1993). Based on clinical work with sexually abused women, these writings uniformly contend that survivors' intimate relationships are marked by an array of abuse-related difficulties including deficits in communication, intimacy, trust, and sexual functioning. The small number of empirical investigations in this area (e.g., DiLillo \& Long, 1999; Hunter, 1991) generally supports this supposition.

The methods used by couples to resolve interpersonal conflict are among the most crucial dimensions on which to assess intimate relationships. The use of physical violence, for example, can be an especially damaging means of settling differences that arise between partners. In addition to the obvious physical harm that can result, such tactics are strongly associated with mental health problems for women (Golding, 1999) as well as being predictive of later separation and divorce (Rogge \& Bradbury, 1999). Several studies have found that women with a history of sexual abuse experience an increased risk of suffering additional interpersonal victimizations as adults, one form of which appears to be physical abuse occurring in the context of couple relationships (Banyard, Arnold, \& Smith, 2000; Briere \& Runtz, 1987; Herman \& Hirschman, 1981; Russell, 1986; Walker, 1984). Representative of these findings are those of Russell (1986), who found that $27 \%$ of incest victims had husbands who "had been physically violent toward them" (p. 160 ); this compared with only $12 \%$ of nonincestuously abused women. However, previous research on this topic has assessed intimate partner violence in only the most general fashion, often through a single interview question or in studies lacking explicit statistical comparisons of violence characteristics between CSA survivors and groups of nonabused women. In addition, some of this work (e.g., Banyard et al., 2000) investigated only the violent acts committed by male partners 
against women. Although this is understandable considering the greater severity of male-versus female-initiated aggression (O'Leary et al., 1989), a more complete understanding of these conflicts may be gained from an examination of the overall directional patterns of violence that occur in survivors' couple relationships.

The present study seeks to extend current knowledge about the nature of interpartner violence among CSA survivors. Here, behavioral descriptors of intimate partner aggression as well as data concerning the directional patterns of that violence (e.g., the extent to which men, women, or both are participants vs. solely the targets of violent acts) were gleaned from interviews with a group of lowincome women. Statistical comparisons of interpartner aggression were made between those women who reported a history of childhood sexual abuse and those who did not. These comparisons are intended to increase current understanding of the phenomenon of couple violence among CSA survivors as well as raise additional questions for future research.

\section{METHOD}

\section{Participants}

To the extent that CSA and partner violence are related, it made sense to examine this association in a sample that may be at high risk for experiencing the primary outcome of interest-intimate partner violence. The present sample was characterized by a constellation of factors that collectively increase the risk of child maltreatment and/or family violence in general (cf. Daro, 1988; Straus \& Gelles, 1990). Women were recruited from local chapters of the federal Women, Infants, and Children (WIC) Nutrition Program and were first screened for inclusion criteria during an interview following WIC nutrition classes or by telephone if time did not permit an on-site interview. These criteria included low income (defined by Medicaid eligibility criteria), at least one child between the ages of 18 and 59 months, and no more than 2 years of post-high school education. Women also must have reported high levels of anger toward their children and the use of physical punishment as a form of discipline on at least one occasion. Those who met these high-risk criteria were invited to participate in two paid assessment sessions to be conducted in their homes. From a total of 290 women who agreed to participate in the assessments, 240 were currently involved in romantic relationships with men and thus included in the present analyses. 


\section{Interviewers}

Interviewers who conducted the data collection were two male and eight female research assistants, all of whom were graduate students in clinical psychology, counseling psychology, or social work, with the exception of one female research assistant who had several years of social services experience. All interviewers were uninformed as to the specific hypotheses of the study.

\section{Measures}

Childhood sexual abuse. As noted, women participated in two assessment sessions involving structured clinical interviews. The same research assistant conducted both interviews, with the assessments of childhood sexual experiences occurring in the second session to allow time for a supportive rapport to be established with participants. Interviews were audiotaped rather than written to allow interviewers to respond attentively and sensitively to participants. The actual screening for sexual abuse was preceded by a statement explaining the sensitive nature of the question to follow (i.e., that participants would next be queried about sexual experiences that they may have had prior to the age of 18). A single interview question was then used to inquire about the occurrence of sexual abuse during childhood. Women were asked:

When you were a child, that is, under the age of 18 , was anyone ever sexually inappropriate with you? What I mean by sexually inappropriate is someone showing you or asking you to show them private parts of the body, or sexual kissing or fondling or other sexual activity with an adult, or with another child who was more than three years older than you at the time.

Due to the sensitive nature of this information, those women responding affirmatively to this question were not asked to verbalize the specific details of their sexual abuse histories. They were instead provided with cards containing a list of numbered descriptors or options for the type of abuse they may have experienced. These descriptors included vaginal and anal intercourse, oral and manual stimulation, sexual kissing (i.e., intimate kissing that was not appropriate to the relationship), exposure of their own genitals, and exposure to someone else's genitals. Women were able to respond by merely stating which numbered responses were true of them. CSA was coded present for those women reporting such activities. For the purposes of the present analyses, only women who reported interactions involving actual physical contact (i.e., not those who reported exposure only) were 
included in the sexually abused group. Participants also provided information on the identity and age of the perpetrator or perpetrators, their own age at the time of the abuse, and whether the abuse occurred once or lasted less than 6 months, less than 2 years, or more than 2 years. ${ }^{1}$

Conflict in current intimate relationships. During the clinical interview, interviewers inquired about discord in participants' current romantic relationships by saying, "Now I am going to talk to you about the times when verbal or physical conflict may have been a part of your romantic relationships with men. Here are some words that describe different types of conflict." Participants were then handed a card containing very specific behavioral descriptors of various acts of verbal and physical conflict. The list included yelling and screaming, swearing, throwing things, hitting, kicking, verbal humiliation, breaking things, threatening with object, verbal threats, hitting with objects, threatening with weapon, and beating. In keeping with the overall structure of the interview, which focused on the woman's opinions, relationships, and behaviors, participants were first asked about their own use of these behaviors. Each woman was told, "We'll start with the things that you do to (current partner's name)." Once the participant had stated the numbers for all of the listed options that she had ever done to her current partner, she was asked to do the same for all of the listed options that her current partner had ever done to her.

Demographics. Finally, a variety of demographic information was collected from participants including their age, racial/ethnic background, marital status, employment status, and highest level of education completed.

\section{Procedure}

Interviewer training. All research assistants were trained to competently deliver the clinical interview by memorizing and practicing the interview with other research assistants. A fellow interviewer accompanied each research assistant to his or her first three administrations of the interview with study participants. Following each of the first three administrations, the accompanying interviewer provided constructive feedback. Once the project coordinator had evaluated one audiotaped interview, a research assistant was permitted to conduct the interviews independently. The tape-recorded interviews were later transcribed and coded into a data entry format by a team of undergraduate research assistants who were supervised by a senior research assistant. 


\section{RESULTS}

\section{Demographic Characteristics}

Comparisons revealed no significant differences between the CSA and noCSA groups on mother's age, race, or employment status (see Table 1). There were statistical (although probably not meaningful) differences on education level, with means of 11.6 and 12.0 for the CSA and no-CSA groups, respectively, $t(216)=2.34, p<.05$. A chi-square analysis revealed that marital status for the CSA group differed significantly from the no-CSA group, with more divorced women in the CSA group and, conversely, more married and single women in the no-CSA group.

\section{Sexual Abuse Parameters}

Women in the CSA group experienced a first episode of abuse at a mean age of 8.8 years $(S D=3.9)$; Table 2 describes ages and types of abuse. More than one third of the women were victims of two or more perpetrators, and $58 \%$ were victims of incest at some point in their childhood. The majority of women were first abused by an unrelated male, a category that includes people who were familiar to the victim (e.g., mother's boyfriend) and people who were unfamiliar to the victim (e.g., a stranger). Most victims were 15 or more years younger than their perpetrator. The duration of abuse was generally either a single incident or more than 2 years, and nearly one half of the women experienced penetration.

\section{Conflict in Current Relationships}

Chi-square analyses compared women in the CSA group and no-CSA group with respect to the presence or absence of any partner violence, with results revealing more women in the CSA group's having experienced at least one incident of partner violence, $\chi 2=12.12(1), p<.005$. Chi-squares were also used to examine the presence or absence of seven specific types of partner conflict across the CSA and no-CSA groups. Holm's sequential Bonferroni method was applied to establish an upper limit for Type I error across the seven comparisons at alpha = .10. As shown in Table 3, women in the CSA group experienced more breaking things, threats with objects, threats with weapons, hitting or kicking, hitting with 
TABLE 1: Demographic Characteristics by Childhood Sexual Abuse Status

\begin{tabular}{|c|c|c|c|c|c|}
\hline & \multicolumn{2}{|c|}{$\operatorname{CSA}(\mathrm{n}=113)$} & \multicolumn{2}{|c|}{ No $\operatorname{CSA}(\mathrm{n}=127)$} & \multirow[b]{2}{*}{ Significance Level } \\
\hline & $\mathrm{M}$ & SD & $\mathrm{M}$ & SD & \\
\hline Woman's age (years) & 26.2 & 5.8 & 26.1 & 6.0 & ns \\
\hline \multirow[t]{3}{*}{ Education (years) } & 11.6 & 1.3 & 12.0 & 1.0 & + \\
\hline & \multicolumn{5}{|c|}{ Percentage of Sample } \\
\hline & \multicolumn{2}{|c|}{$\operatorname{CSA}$} & \multicolumn{2}{|c|}{ No CSA } & Significance Level \\
\hline Race & & & & & $n s$ \\
\hline African American & \multicolumn{2}{|c|}{27} & \multicolumn{2}{|c|}{28} & \\
\hline Caucasian & \multicolumn{2}{|c|}{69} & \multicolumn{2}{|c|}{63} & \\
\hline Other minority & \multicolumn{2}{|c|}{5} & \multicolumn{2}{|c|}{9} & \\
\hline Marital status & \multirow{2}{*}{\multicolumn{2}{|c|}{37}} & & & + \\
\hline Married & & & \multicolumn{2}{|c|}{44} & \\
\hline Divorced & \multicolumn{2}{|c|}{17} & \multicolumn{2}{|c|}{5} & \\
\hline Single & \multicolumn{2}{|c|}{34} & \multicolumn{2}{|c|}{43} & \\
\hline Separated & \multicolumn{2}{|c|}{12} & \multicolumn{2}{|c|}{8} & \\
\hline Employed & \multicolumn{2}{|c|}{47} & \multicolumn{2}{|c|}{46} & $n s$ \\
\hline
\end{tabular}

NOTE: CSA = Childhood sexual abuse.

${ }^{+} p<.05$.

objects, and beating. Only throwing things was not significantly higher in the CSA group.

Although the analyses presented so far addressed the relation between partner violence and a history of childhood sexual abuse in general, we also wished to explore whether our data would reveal a contribution of sexual abuse severity to the probability of partner violence. This was accomplished by examining the association between several abuse characteristics commonly found to predict poorer longterm adjustment among women (Beitchman et al., 1992) and later intimate partner violence. For each participant, the presence of incest, penetration, duration, and multiple perpetrators was coded dichotomously. Penetration was designated present if the participant reported oral, vaginal, or anal intercourse, and duration was designated as either a single instance or more than one instance of abuse. Each of these severity indices was then crossed with the presence or absence of self-reported partner violence and chi-square tests of association computed. No significant associations emerged from these analyses.

We next sought to shed light on the directional patterns of the partner conflict in our sample. As noted, women had been asked to specify which member of the cou- 
TABLE 2: Parameters of Sexual Abuse

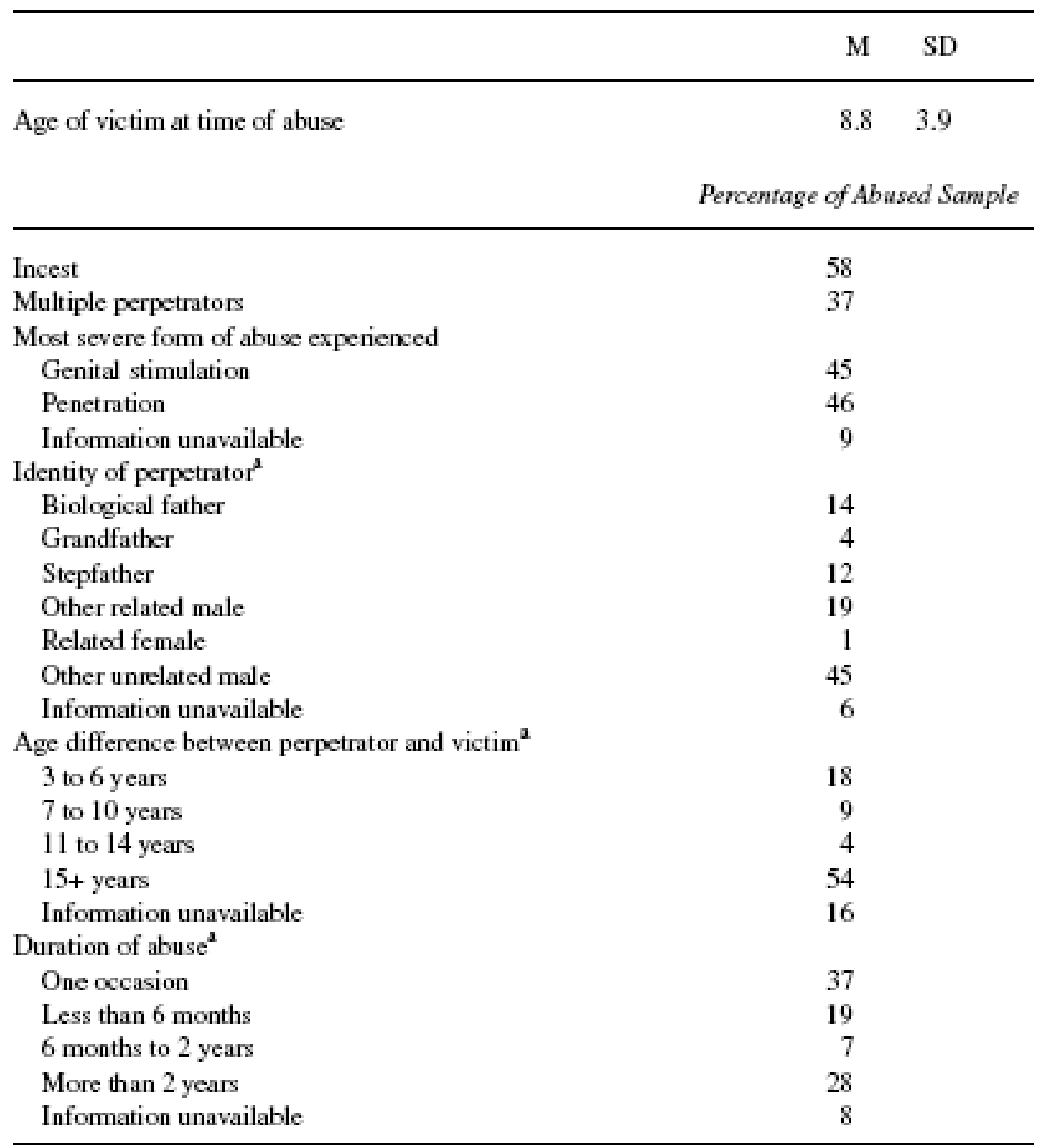

a. Data based on the first abuse incident for participants who were abusod by multiple perpetrators.

ple had committed any of several physically violent acts (hitting and kicking, hitting with objects, and beating) against the other. On the basis of these responses, three mutually exclusive categories were formed: those who reported only physical aggression committed by their partners against themselves, those who reported only physical aggression committed by themselves against their partners, and those who reported acts committed by both partners against the other at some time in their relationship. Three chi-square tests comparing abused and nonabused par- 
TABLE 3: Frequency of Conflict Behaviors in Current Relationships by Childhood Sexual Abuse Status $(N=240)$

\begin{tabular}{|c|c|c|c|c|c|c|}
\hline $\begin{array}{l}\text { Type of } \\
\text { Conflict }\end{array}$ & $\begin{array}{c}\text { Percentage } \\
\text { CSA } \\
(\mathrm{n}=113)\end{array}$ & $\begin{array}{c}\text { Percentage } \\
\text { No CSA } \\
(\mathrm{n}=127)\end{array}$ & $\begin{array}{c}\chi^{2} \\
(\mathrm{df}=l)\end{array}$ & $\mathrm{p}$ & $\begin{array}{c}\text { Critical } \\
\text { Value of } \mathrm{p}^{\mathrm{a}}\end{array}$ & $\begin{array}{c}\text { Significance } \\
\text { Level }\end{array}$ \\
\hline Hitting or kicking & 31 & 17 & 6.97 & .008 & .014 & $\rightarrow$ \\
\hline Threatening with weapon & 11 & 2 & 6.96 & .008 & .017 & + \\
\hline Threatening with objects & 13 & 4 & 6.83 & .009 & .020 & $*$ \\
\hline Hitting with objects & 14 & 5 & 6.39 & .011 & .025 & + \\
\hline Beating & 10 & 2 & 5.92 & .015 & .033 & + \\
\hline Breaking things & 25 & 14 & 4.34 & .037 & .05 & + \\
\hline Throwing things & 31 & 24 & 1.64 & .201 & .10 & \\
\hline
\end{tabular}

NOTE: CSA = childhood sexual abuse.

a. Using Holm's sequential Bonferroni method.

${ }^{+} p<.05$.

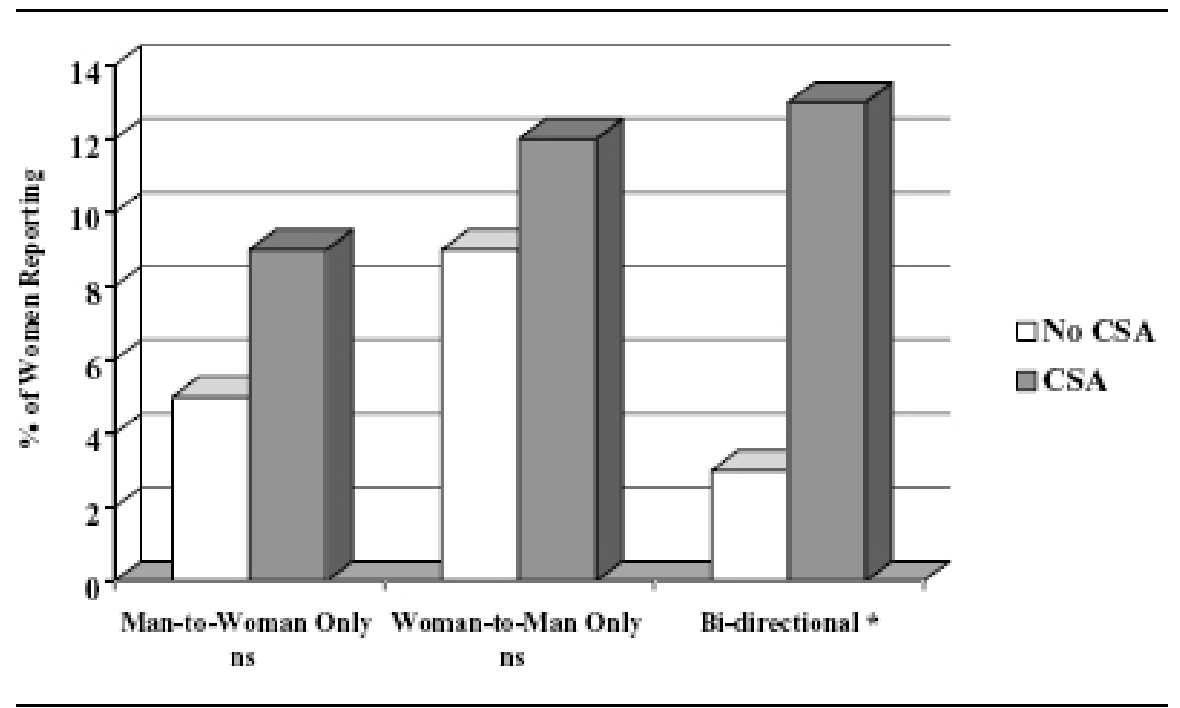

Figure 1: Direction of Aggression by Abuse Status

NOTE: $\chi^{2}(1)=7.73, p<.05 ; n s=$ nonsignificant.

ticipants on each directional category (man-to-woman, woman-to-man, and bidirectional) revealed an uneven distribution in one of the categories such that sexually abused women's relationships were more likely to have involved violence that at some point in time had been perpetrated by both members of the couple. Figure 1 depicts the distribution of participants across the directional categories by CSA status. Visual examination of Figure 1 also revealed an unexpected pattern show- 
ing that a significant percentage of all women, regardless of their sexual abuse history, reported the occurrence of at least one incident of woman-to-man violence in the absence of any male-initiated aggression.

\section{DISCUSSION}

Of the 240 women who participated in this study, $47 \%$ reported experiencing some form of contact sexual abuse as children. This figure exceeds that found in most other community studies (cf. Finkelhor, 1994). One reason for this discrepancy might be the relatively broad definition of contact sexual abuse used here. Although our criteria excluded noncontact offenses, the upper age limit of 18 and minimum 3-year age difference (rather than 5) between perpetrator and victim may have resulted in a greater number of childhood sexual experiences' being classified as abusive. The rate of abuse found here is not entirely unique in the literature, however. Using a similarly broad definition of contact CSA, Wyatt, Guthrie, and Notgrass (1992) found that $45.2 \%$ of their largely African American sample reported a history of sexual abuse.

The primary objective of this study was to uncover heretofore unknown details about the nature and characteristics of physical conflict occurring in the dyadic relationships of women who have been sexually abused as children. The CSA survivors interviewed here were twice as likely as nonabused women to report at least one instance of physical violence in their current couple relationships $(17 \%$ vs. $34 \%$ ). Although the overall rate of violence among survivor couples in the present study is in general accordance with those reported by previous investigators (40\% by Banyard et al., 2000; 49\% by Briere \& Runtz, 1987; 27.5\% by Herman \& Hirschman, 1981; 27\% by Russell, 1986), it is greater than some national estimates suggesting that violence between spouses occurs in approximately one out of every six (16.5\%) households annually (Straus \& Gelles, 1986). Further examination of the specific behavioral characteristics of the violence reported showed the pattern of increased physical conflict among survivor couples to be evident across several severe acts of aggression, including hitting, kicking, hitting with objects, and beating. Our failure to find a strong association between individual abuse characteristics (i.e., incest, penetration, duration, and number of perpetrators) and partner violence suggests that in our sample, the presence of any childhood sexual abuse may have had a sufficiently toxic effect on adult partner relations to overwhelm any additional contribution of our relatively crude severity measures. Still, the consistent association between CSA and adult physical victim- 
ization, found both here and in prior investigations, is troublesome, particularly in light of findings suggesting that increased long-term difficulties (e.g., anxiety, depression, and dissociation) are associated with the cumulative impact of multiple victimizations experienced by survivors as both children and adults (Follette, Polusny, Bechtle, \& Naugle, 1996).

In addition to bolstering past data suggesting that CSA may leave women at an increased risk for later intimate partner violence, this investigation extended current knowledge by examining the directional patterns of aggression reported by participants. Our analyses of these patterns revealed two primary findings worthy of elaboration. First, whereas previous investigations with CSA survivors have focused on man-to-woman aggression only, the present data link CSA to a greater likelihood of mutually inflicted couple violence. Here, a significantly greater number of CSA survivors' relationships were reported to have involved physical violence that at some point in time had been committed by both members of the couple (as indicated by the bidirectional category in Figure 1). Findings that violence within relationships is often committed by both members of the couple are certainly not without precedent in the literature (e.g., Bradbury \& Lawrence, 1999; Stets \& Straus, 1989; Straus \& Gelles, 1990). It should be emphasized, however, that although female survivors may play an active role in a portion of the physical altercations occurring in their relationships, the aggression reported by the current participants (as well as women in general) may often serve a self-protective or defensive function enacted in response to a physical altercation initiated by a male partner (Nazroo, 1995; Saunders, 1986; Straus \& Gelles, 1990). Furthermore, female acts of aggression are likely to be less severe, involving pushing, slapping, or grabbing rather than full-fledged beatings (O'Leary et al., 1989).

A second point of interest concerns the number of women, regardless of sexual abuse history, who reported engaging in unreciprocated acts of violence against their male partners. Here, a large proportion of all intimate relationships ( $12 \%$ for survivors and $9 \%$ for nonabused women) were said to have involved at least one instance of woman-to-man aggression in the absence of any maleinitiated aggression whatsoever. In fact, as depicted in Figure 1, the percentage of participants who reported only occurrences of woman-to-man violence appeared to exceed that in which only man-to-woman aggression was reported. This result is consistent with two large-scale studies finding that a substantial number of both women and men reported using physical aggression when their partners did not (Brush, 1990; Straus \& Gelles, 1988). Nevertheless, the possibility remains that even unreciprocated aggression may be defensive in nature, particularly if the aggression occurs in response to an ongoing situation 
perceived by women to pose an imminent threat of harm from a male partner (Browne, 1987).

Several authors have noted that investigations focusing exclusively on the specific aggressive acts committed by partners are limited by a lack of attention to the broader context, meaning, and impact of that aggression (Dobash, Dobash, Wilson, \& Daly, 1992; H. Johnson, 1998; Kurz, 1993). Similar qualifications should be made about the present study. We assessed only the presence or absence of physical conflict in relationships, not the per-couple frequency with which violent altercations may have occurred. Thus, it is quite possible that the female-precipitated violence reported here actually occurred less often than male-initiated aggression. Furthermore, our analyses of the topographic features of violence did not include a measure of the severity or impact of those acts on victims. As noted, this is of particular significance considering the evidence showing that physical abuse committed by women tends to be less severe and is less likely to result in serious injury than that committed by men (Cantos, Neidig, \& O'Leary, 1994; Holtzworth-Munroe, Beatty, \& Anglin, 1995; Nazroo, 1995; O'Leary et al., 1989). Finally, because the present sample included only low-income childbearing women, it represented a fairly narrow set of demographic characteristics, which limits our ability to generalize findings to the broader population of women who have experienced child sexual abuse.

Methodological issues notwithstanding, this study sheds new light on the nature of violence in the intimate relationships of female CSA survivors by suggesting that both male and female partners may sometimes direct a variety of assaultive behaviors toward each other. In attempting to reconcile the often disparate findings concerning gender patterns of partner violence, M. P. Johnson (1995) posited that two rather distinct patterns of intimate partner violence may occur in this country. The first pattern, said to be common among women contacting clinics and social services agencies (e.g., domestic violence shelters), is terroristic in nature and characterized by frequent and escalating physical abuse initiated by men against female partners in an effort to exert general control over them. The second pattern, more typical of community samples, is characterized by a less frequent and nonescalating form of violence occurring on occasions when conflict "gets out of hand." This latter pattern is thought to be initiated with approximately equal frequency by both men and women. The presence of both types of partner abuse may have been reflected in our sample, which was drawn from the community yet shared some similarities with clinical populations (e.g., elevated anger and at risk for child abuse). It is conceivable, for instance, that the severe abuses of adult authority and boundary violations that accompany child sexual abuse may 
undermine survivors' sense of personal control and autonomy, leaving them vulnerable to the powerful control tactics that are a part of terroristic abuse. Greater sensitivity to violations of interpersonal control may alternatively contribute to increased defensive (or occasionally offensive) acts of physical aggression in response to perceived threat - a pattern more consistent with common couple violence. Either of these possibilities fits with the popular theoretical notion that issues related to powerlessness are a lasting issue for many CSA survivors (Finkelhor \& Browne, 1985). Finally, apart from the abuse per se, findings that survivors' families of origin are often characterized by marital dysfunction and conflict (Fergusson, Horwood, \& Lynskey, 1996; Mullen, Martin, Anderson, Romans, \& Herbison, 1993; Stern, Lynch, Oates, O'Toole, \& Cooney, 1995) suggest that many survivors may have little opportunity to observe and learn effective nonviolent approaches to conflict resolution with partners.

Although this study provides a closer examination of the problem of intimate partner violence in a community sample of CSA survivors, many important aspects of this complex phenomenon have yet to be explored. Future investigations of the topographic features of this violence will need to include both members of the couple to explore the gender symmetry versus asymmetry of aggression, the frequency and severity of abusive acts, patterns of escalation, and the extent of abuse-related injuries and hospitalizations resulting from couple violence among CSA survivors. A more contextually sensitive appraisal of couple violence among CSA survivors will also be required. Such analyses might explore issues of communication, power and control, conflict response tactics, and impulse control as a means to gain insight into the interpersonal dynamics that underlie couple violence experienced by CSA survivors. Qualitative research designs represent one useful tool for obtaining initial data on these dimensions of couple functioning. A careful contextual analysis of intimate partner violence involving the assessment of female survivors and their male partners holds promise for elucidating key variables appropriate for later quantitative analysis and, ultimately, intervention.

\section{NOTE}

1. After participants had been preliminarily classified as having either experienced or not experienced childhood sexual abuse (CSA) (based on the criteria noted in the text), data for each participant were individually examined to ensure that sexual abuse status had been coded correctly. This process revealed four cases in which women reported sexual relationships with men who were 3 to 
5 years older than themselves during a time when the participants were between the ages of 16 and 18. Although these cases technically met our criteria for CSA, examination of the audiotaped interviews revealed these experiences to be consensual dating relationships that were judged not to constitute sexual abuse. These 4 participants were therefore classified as non-sexually abused.

\section{REFERENCES}

Banyard, V. L., Arnold, S., \& Smith, J. (2000). Childhood sexual abuse and dating experiences of undergraduate women. Child Maltreatment, 5, 39-48.

Beitchman, J. H., Zucker, K. J., Hood, J. E., DaCosta, G. A., Akman, D., \& Cassavia, E. (1992). A review of the long-term effects of child sexual abuse. Child Abuse and Neglect, 16, 101-118.

Bradbury, T. N., \& Lawrence, E. (1999). Physical aggression and the longitudinal course of newlywed marriage. In X. B. Arriaga \& S. Oskamp (Eds.), Violence in intimate relationships (pp. 181-202). Thousand Oaks, CA: Sage.

Briere, J., \& Runtz, M. (1987). Post-sexual abuse trauma: Data and implications for clinical practice. Journal of Interpersonal Violence, 2, 367-397.

Browne, A. (1987). When battered women kill. New York: Free Press.

Browne, A., \& Finkelhor, D. (1986). Impact of child sexual abuse: A review of the research. Psychological Bulletin, 99, 66-77.

Brush, L. D. (1990). Violent acts and injurious outcomes in married couples: Methodological issues in the National Survey of Families and Households. Gender and Society, 4, 56-67.

Cameron, G. (1995). What about me? A guide for men helping female partners deal with childhood sexual abuse. Carp, Ontario, Canada: Creative Bound.

Cantos, A. L., Neidig, P. H., \& O’Leary, K. D. (1994). Injuries of women and men in a treatment program for domestic violence. Journal of Family Violence, 9, 113-124.

Courtright, J., \& Rogers, S. (1994). Your wife was sexually abused. Grand Rapids, MI: Zondervan.

Daro, D. (1988). Confronting child abuse research for effective program design. New York: Free Press.

Davis, J. L., \& Petretic-Jackson, P. (2000). The impact of child sexual abuse on adult interpersonal functioning: A review and synthesis of the empirical literature. Aggression and Violent Behavior: A Review Journal, 5, 291-328.

Davis, L. (1991). Allies in healing. New York: HarperCollins.

DeBeixedon, Y. S. (1995). Lovers and survivors: A partner's guide to living with and loving a sexual abuse survivor. San Francisco: Robert D. Reed.

DiLillo, D. (in press). Interpersonal functioning among women reporting a history of child sexual abuse: Empirical findings and methodological issues. Clinical Psychology Review.

DiLillo, D., \& Long, P. J. (1999). Perceptions of couple functioning among female survivors of child sexual abuse. Journal of Child Sexual Abuse, 7(4), 59-76.

Dobash, R. P., Dobash, R. E., Wilson, M., \& Daly, M. (1992). The myth of sexual symmetry in marital violence. Social Problems, 39, 71-91. 
Engel, B. (1993). Partners in recovery: How mates, lovers, and other prosurvivors can learn to support and cope with adult survivors of childhood sexual abuse. Los Angeles: Lowell House.

Fergusson, D. M., Horwood, J. L., \& Lynskey, M. T. (1996). Childhood sexual abuse and psychiatric disorders in young adulthood. Part II. Psychiatric outcomes of sexual abuse. Journal of the American Academy of Child and Adolescent Psychiatry, 35, 1365-1374.

Finkelhor, D. (1994). Current information on the scope and nature of child sexual abuse. The Future of Children, 4, 31-53.

Finkelhor, D., \& Browne, A. (1985). The traumatic impact of child sexual abuse: A conceptualization. American Journal of Orthopsychiatry, 55, 530-541.

Follette, V. M., Polusny, M. A., Bechtle, A. E., \& Naugle, A. E. (1996). Cumulative trauma: The impact of child sexual abuse, adult sexual assault, and spouse abuse. Journal of Traumatic Stress, 9, 25-35.

Gil, E. (1992). Outgrowing the pain together: A book for spouses and partners of adults abused as children. New York: Bantam Books.

Golding, J. M. (1999). Intimate partner violence as a risk factor for mental disorders: A meta-analysis. Journal of Family Violence, 14, 99-133.

Graber, K. (1991). Ghosts in the bedroom: A guide for incest survivors. Deerfield Beach, FL: Health Communications.

Hansen, P. (1991). Survivors and partners: Healing the relationships of adult survivors of child sexual abuse. Longmont, CO: Heron Hill.

Herman, J. L., \& Hirschman, L. (1981). Father-daughter incest. Cambridge, MA: Harvard University Press.

Holtzworth-Munroe, A., Beatty, S. B., \& Anglin, K. (1995). The assessment and treatment of marital violence: An introduction for the marital therapist. In N. S. Jacobson \& A. S. Gurman (Eds.), Clinical handbook of couple therapy (pp. 317-339). New York: Guilford.

Hunter, J. A. (1991). A comparison of the psychosocial maladjustment of adult males and females sexually abused as children. Journal of Interpersonal Violence, 6, 205-217.

Johnson, H. (1998). Rethinking survey research on violence against women. In R. E. Dobash \& R. P. Dobash (Eds.), Rethinking violence against women (pp. 23-51). Thousand Oaks, CA: Sage. Johnson, M. P. (1995). Patriarchal terrorism and common couple violence: Two forms of violence against women. Journal of Marriage and the Family, 57, 283-294.

Kritsberg, W. (1990). Healing together. Deerfield Beach, FL: Health Communications.

Kurz, D. (1993). Physical assaults by husbands: A major social problem. In R. J. Gelles \& D. R. Loseke (Eds.), Current controversies on family violence (pp. 88-103). Newbury Park, CA: Sage.

Levine, R. B. (1996). When you are the partner of a rape or incest survivor: A workbook for you. San Jose, CA: Resource Publications.

Matsakis, A. (1998). Trust after trauma: A guide to relationships for survivors and those who love them. Oakland, CA: New Harbinger Publications.

Mullen, P. E., Martin, J. L., Anderson, J. C., Romans, S. E., \& Herbison, G. P. (1993). Child sexual abuse and mental health in adult life. British Journal of Psychiatry, 163, 721-732. 
Nazroo, J. (1995). Uncovering gender differences in the use of marital violence: The effect of methodology. Sociology, 29, 475-494.

O’Leary, K. D., Barling, J., Arias, I., Rosenbaum, A., Malone, J., \& Tyree, A. (1989). Prevalence and stability of physical aggression between spouses: A longitudinal analysis. Journal of Consulting and Clinical Psychology, 57, 263-268.

Polusny, M. M., \& Follette, V. M. (1995). Long-term correlates of childhood sexual abuse: Theory and empirical findings. Applied and Preventive Psychology, 4, 143-166.

Rogge, R. D., \& Bradbury, T. N. (1999). Till violence does us part: The differing roles of communication and aggression in predicting adverse marital outcomes. Journal of Consulting and Clinical Psychology, 67, 340-351.

Russell, D.E.H. (1986). The secret trauma: Incest in the lives of girls and women. New York: Basic Books.

Saunders, D. G. (1986). When battered women use violence: Husband-abuse or self-defense? Violence and Victims, 1, 47-60.

Stark, K. (1993). Helping the adult survivor of child sexual abuse: For friends, family, and lovers. Racine, WI: Mother Courage Press.

Stern, A. E., Lynch, D. L., Oates, R. K., O’Toole, B. L., \& Cooney, G. (1995). Self-esteem, depression, behavior, and family functioning in sexually abused children. Journal of Child Psychology and Psychiatry, 36, 1077-1089.

Stets, J. E., \& Straus, M. A. (1989). The marriage license as a hitting license: A comparison of assaults in dating, cohabiting, and married couples. Journal of Family Violence, 4, 161-180.

Straus, M. A., \& Gelles, R. J. (1986). Societal change and change in family violence from 1975 to 1985 as revealed by two national samples. Journal of Marriage and the Family, 48, 465-479.

Straus, M. A., \& Gelles, R. J. (1988). Violence in American families: How much is there and why does it occur? In E. W. Nunnally, C. S. Chilman, \& F. M. Fox (Eds.), Troubled relationships (pp. 141-162). Newbury Park, CA: Sage.

Straus, M. A., \& Gelles, R. J. (1990). Societal change and change in family violence from 19751985 as revealed by two national surveys. In M. A. Straus \& R. J. Gelles (Eds.), Physical violence in American families: Risk factors and adaptations to violence in 8,145 families (pp. 113131). New Brunswick, NJ: Transaction.

Walker, L.E.A. (1984). Battered woman syndrome. New York: Springer.

Wyatt, G., Guthrie, D., \& Notgrass, C. M. (1992). Differential effects of women's child sexual abuse and subsequent sexual revictimization. Journal of Consulting and Clinical Psychology, 60, 167-173.

David DiLillo received a Ph.D. in clinical psychology from Oklahoma State University in 1997. $\mathrm{He}$ is currently an assistant professor of psychology at the University of Nebraska-Lincoln. His primary research interests lie in the area of family violence, particularly the long-term interpersonal adjustment of those who have experienced various forms of childhood trauma and maltreatment. He maintains a secondary research interest in the etiology, prevention, and psychological consequences of unintentional injury. 
Dawn Giuffre is a doctoral candidate in clinical psychology at the University of Missouri-Columbia. Her research interests include the effects of childhood sexual abuse on adult adjustment and chronic illness in children.

George C. Tremblay received his doctorate in clinical psychology from the University at Albany (SUNY) in 1996, following completion of a predoctoral internship at the University of Mississippi and Veterans Affairs Medical Centers in Jackson, MS. His research and clinical interests revolve around child and adolescent behavior, parenting and couple relationships, child maltreatment, and developmental psychopathology.

Lizette Peterson is the Byler Endowed Chair of Psychology at the University of Missouri-Columbia and has authored more than 160 articles, books, and empirical papers. Her early work focused on the prevention of distress in child surgery patients. More recent work lies in the area of injury prevention in children as well as the prevention of child abuse and neglect. She serves on the editorial boards of several clinical and health psychology journals. 